\title{
Ice Crystal Icing Engine Testing in the NASA Glenn Research Center's Propulsion Systems Laboratory: Altitude Investigation
}

\author{
Michael J. Oliver \\ NASA Glenn Research Center
}

Copyright @ 2014 SAE International

\begin{abstract}
The National Aeronautics and Space Administration (NASA) conducted a full scale ice crystal icing turbofan engine test using an obsolete Allied Signal ALF502-R5 engine in the Propulsion Systems Laboratory (PSL) at NASA Glenn Research Center. The test article used was the exact engine that experienced a loss of power event after the ingestion of ice crystals while operating at high altitude during a 1997 Honeywell flight test campaign investigating the turbofan engine ice crystal icing phenomena. The test plan included test points conducted at the known flight test campaign field event pressure altitude and at various pressure altitudes ranging from low to high throughout the engine operating envelope. The test article experienced a loss of power event at each of the altitudes tested. For each pressure altitude test point conducted the ambient static temperature was predicted using a NASA engine icing risk computer model for the given ambient static pressure while maintaining the engine speed.
\end{abstract}

\section{Introduction}

Pilots have experienced uncommanded thrust reductions while operating near convective storms during high altitude flights since the early 1950's [1]. These events are suspected as due to the ingestion of ice crystals into the turbofan engines powering the aircraft. The theory is that a phenomena termed ice crystal icing is occurring on warmer than freezing surfaces inside the engines operating at high altitudes due to the ingestion of ice crystals [2]. Several loss of thrust events occurred during the 1990's on BAe 146 aircraft powered by AlliedSignal ALF502-R5 turbofan engines. This led to an investigation and resolution program conducted by Honeywell Engines [3]. The investigation included flight testing of an instrumented engine and aircraft that allowed for the continuous monitoring of engine and ambient flight conditions as the aircraft flew through ice crystal icing conditions near convective storms. During these flight tests a loss of thrust event occurred while both engine operating parameters and ambient flight conditions were being recorded. This data was made available to NASA by Honeywell Engines.

To better understand this ice crystal icing phenomenon and to develop full scale engine, driven rig and component test capability in high altitude ice crystal icing conditions, NASA Glenn Research Center in Cleveland, $\mathrm{OH}$ modified test cell 3 in Page 1 of 7 the PSL, an existing altitude simulation engine test facility [4] with an ice crystal cloud generation system. The PSL cloud generation system/facility was calibrated to duplicate the ice crystal icing field event from the BAe146 flight test campaign [5]. NASA conducted an inaugural full scale ice crystal icing turbofan engine test in the modified PSL in February 2013. The instrumented engine that experienced the flight test event is the same serial number (LF01) engine that was used for the NASA PSL inaugural ice crystal icing engine testing. This testing is documented and detailed in reference [6].

The data generated during this testing contained three subsets: known high altitude event conditions, altitude scaling conditions and a design of experiment (DOE) data set. The flight test data supplied by Honeywell Engines was the basis for the known event conditions portion of the test plan. The altitude scaling portion of the test plan was designed to duplicate the known flight test event at subsequently lower altitudes. This was done to generate engine test data in order to investigate the feasibility of altitude scaling testing of ice crystal icing in a turbofan engine environment. The DOE portion of the test plan was developed by Honeywell engines in order to investigate sensitivity of the engine performance/operability to various test parameters. The known conditions portion of the test plan is discussed in reference [6] and the DOE portion of the test plan is discussed in reference [7]. The data generated during the altitude scaling portion of the test plan is the basis for this manuscript.

\section{PSL Ice Crystal Icing Altitude Scaling Engine Testing}

\section{Roll Back Testing at Lower Altitudes}

\section{Testing Objectives}

The objective of these altitude scaling test points was to generate engine data to assist researchers in investigating the feasibility of developing altitude scaling laws that would assist engine manufacturers in designing test plans simulating high altitude ice crystal icing tests but conducted at existing sea level engine test facilities [8]. This is required to allow for the testing of large, high air mass flow turbofan engines that cannot be tested in altitude simulation facilities like PSL due to maximum airflow limitations. 


\section{Altitude Scaling Test Plan Development}

The altitude scaling test points were conducted to generate data of a full scale turbofan engine ingesting ice crystals and experiencing a loss of thrust event while operating at altitudes ranging from high to low. The high altitude flight test ice crystal icing event duplicated in PSL was based on a known set of environmental and engine operating conditions. For the altitude scaling portion of the test plan, potential ice crystal icing conditions at lower altitudes leading to an ice crystal icing event were unknown. This presented a difficult task for the development of the altitude scaling portion of the test plan. To address this issue, NASA developed an engine icing risk model based on the geometry and performance maps of the test article and the prediction of icing risk as a function of ingested ice crystal melt ratio and wet-bulb temperature within the flow path. This icing risk model was used to predict the ambient environmental operating temperature for each altitude scaling test point conducted [9]. To facilitate testing by limiting unknowns, the engine operating parameters were not changed between the various altitude scaling test points if possible. Total water content of the cloud and tweaks to engine speed were required changes for some test points.

\section{Key Roll Back Indicating Parameter}

During the PSL ice crystal icing testing, the key indicating parameter of the ice crystal icing event, a compressor roll back, was found to be the initial reduction of the measured load parameter, the average of two measured load cells mounted on the thrust stand [6]. Based on the investigation and resolutions report [3] and the PSL test data analyzed [6], the theory is that ice build-up or ice crystal icing occurs in the low pressure compression (LPC) system for this test article. The ice buildup restricts the core air flow or flow through the high pressure compressor, combustor and high pressure turbine of the engine. The restriction is theorized to be either a physical or aerodynamically induced blockage that limits the airflow and thus the energy able to be produced in the engine core. The reduction in energy produced in the core results initially in a reduction of the core component of engine thrust seen as a small reduction in the measured load parameter and subsequently an uncommanded reduction in N1 or fan speed leading to a reduction in the by-pass component of engine thrust seen as a larger reduction in measured load and if allowed to further continue an eventual sudden uncommanded reduction in $\mathrm{N} 2$ or a full roll back of the high pressure compression system. This is seen as a sudden drop off of N2, N1 and measured load.

\section{Called Roll Back}

A full engine roll back exposes the test article to a high risk of hardware damage due to the shedding of ice buildup in the flow path. In order to mitigate this risk a called roll back procedure was developed. The called roll back procedure requires close monitoring of the measured load parameter, flow path static pressure, metal temperatures, N1 and N2. Once a certain threshold of reduced measured load is met accompanied by observed static pressure, temperature, N1 and N2 losses, a rollback is deemed imminent, the cloud is turned off and the engine is allowed to recover or return to initial cloud off operating condition. The plots shown in Figures 1 to 5 show plots of these parameters or called roll back

Page 2 of 7 indicators charts for selected pressure altitude test conditions conducted on this test article. The plots are presented in decreasing altitude order: Altitude-1 > Altitude-2 > Altitude-3 > Altitude-4 $>$ Altiude-5. Altitude-1 in Figure 1, is the called roll back of the known flight test condition at high altitude tested during the flight test campaign and duplicated in PSL.

\section{Altitude Scaling Test Points}

Each of the altitude scaling test points shown in Figures 1-5 underwent an uncommanded loss of power due to operation in an ice crystal cloud environment produced in PSL. Though the test points conducted are not intended to represent a feasible flying condition the objective of the tests was to produce an ice crystal icing related loss of power event. A major benefit of using the PSL facility is that any test point a researcher wishes to run can be conducted whether it represents a feasible condition for flight or not. This capability to generate altitude scaling data was not possible before the PSL modifications. It can now be used to investigate the feasibility of developing altitude scaling laws [8].

\section{General Discussion about the Plot Scales}

A detailed description is presented in the following sections for each of the altitude scaling test points presented in Figures 1 to 5 . The brief notes listed immediately following this paragraph apply to the scales of all the charts in the figures. It should be noted by the reader that the plots are all sanitized at the request of the engine owner in efforts to protect data deemed proprietary in nature.

\section{Load}

The load data was normalized by the maximum value in each data set before it was plotted. Each load data point represents a relative value rather than an absolute value. The data point is referenced to the maximum value of load measured during the respective test to ascertain whether the load is in general decreasing or increasing as the test point ensues. In all of the plots the load increases slightly at cloud on since the additional mass of the water entrained in the airflow goes to increasing the change in momentum as the air and water mixture passes through the various stages of the engine. For each plot a label is placed showing in general the load decreasing. This label is not intended to identify specifically the onset of load reduction.

\section{Time}

The time scale is not equal for all of the plots. In an effort to facilitate time scale comparisons between the test points the time scale for the reference Altitude-1 test condition is called X. All the other time scales are referenced as some factor of $X$. This allows the reader to easily compare time scales on the sanitized charts.

\section{Cloud}

The cloud plot line is intended to be an on/off indication. When the cloud plot line is not on the X-axis the cloud is turned on for the test point. The cloud was turned off for every test point at the instant a decision was made to call the roll back condition. 


\section{N1, N2, Ps, PLA and Temperature}

The plot scales for all the plots are identical for the parameters of N1, N2, static pressure (Ps), power lever angle (PLA) and flow path metal temperatures. There is a significant difference between cloud on and cloud off metal temperatures measured in the flow path. For each test point presented the load parameter appears to reduce as the metal temperatures appear to converge as the test point ensues. The temperature planes referenced go deeper into the engine as the respective plane number increases. They are all located in the low pressure compression system. Plane 5 temperature converges the fastest for all test points.

\section{Altitude-1}

The chart, Altitude-1, in Figure 1 plots the called roll back data generated in PSL that duplicated the known high altitude ice crystal icing roll back event which occurred during actual flight testing conducted by Honeywell Engines using the LF01 turbofan engine [3]. It is noted that this is the only known environmental and operational roll back condition for any turbofan engine that exists for an ice crystal icing event. The parameters of this figure are used as reference for the altitude scaling test points conducted at lower altitudes.

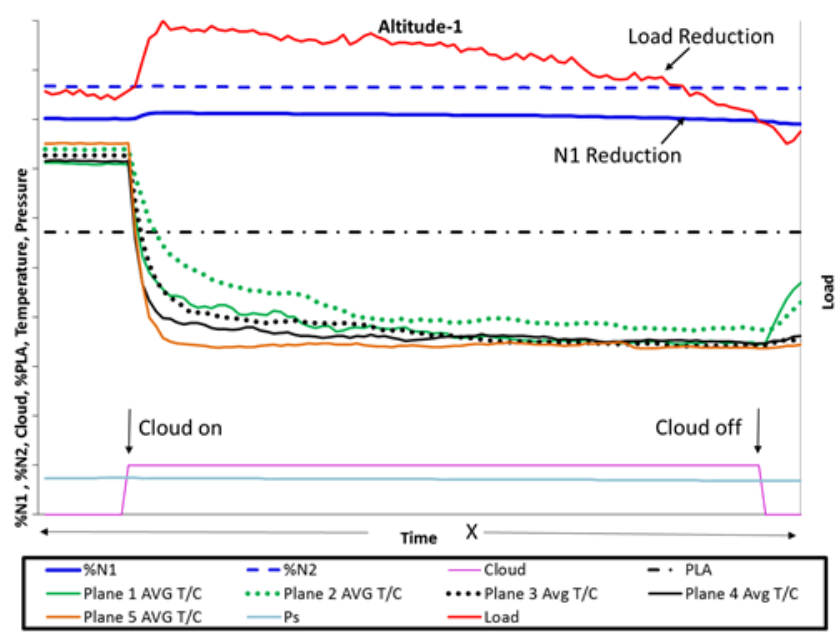

Figure 1. Altitude-1, Roll back indicator chart for the known high altitude flight test condition tested in PSL.

The Load parameter begins to decrease as the average plane temperatures appear to converge. N1 is slightly reduced though PLA is steady for this called roll back test point and an $\mathrm{N} 2$ reduction is not noticeable to the naked eye. Note that the load parameter begins to reduce prior to the reduction of N1 and N2. It is also seen that there is a slight reduction in Ps as the temperatures converge and the load begins to decrease. This plot supports the theory that ice buildup is leading to restricted flow which is manifested as a reduction in load and a reduced static pressure as the air mass flow rate begins to pass through a smaller area.

\section{Altitude-2}

The chart, Altitude-2, in Figure 2 plots the PSL data generated during an ice crystal icing test point conducted at a lower

Page 3 of 7 altitude than Altitude-1. From the chart it can be seen that the time scale for the roll back condition is nearly $4 \mathrm{X}$ longer than the Altitude-1 reference condition. The cloud total water content was held constant for these two test points. The only changes between them were the ambient static temperature and pressure. The plane temperatures do not converge as quickly as they did for the reference condition. N1 and Ps are reduced slightly and the $\mathrm{N} 2$ reduction is not visible on the plot. PLA remains constant. This result supports the theory that the large temperature drop at cloud on for the average plane temperatures may be related to the wet-bulb temperature at the surface as water on the surface where the thermocouples are embedded evaporates into the airflow and the air temperature approaches the adiabatic saturation temperature. The increased time to cool down the metal temperatures at the lower altitude may be related to the fact that at the higher pressures of the lower altitude the evaporation potential is lower and is not as readily occurring from the surface. Indeed it can be seen that the static pressure is higher along the flow path for altitude- 2 than for the reference condition.

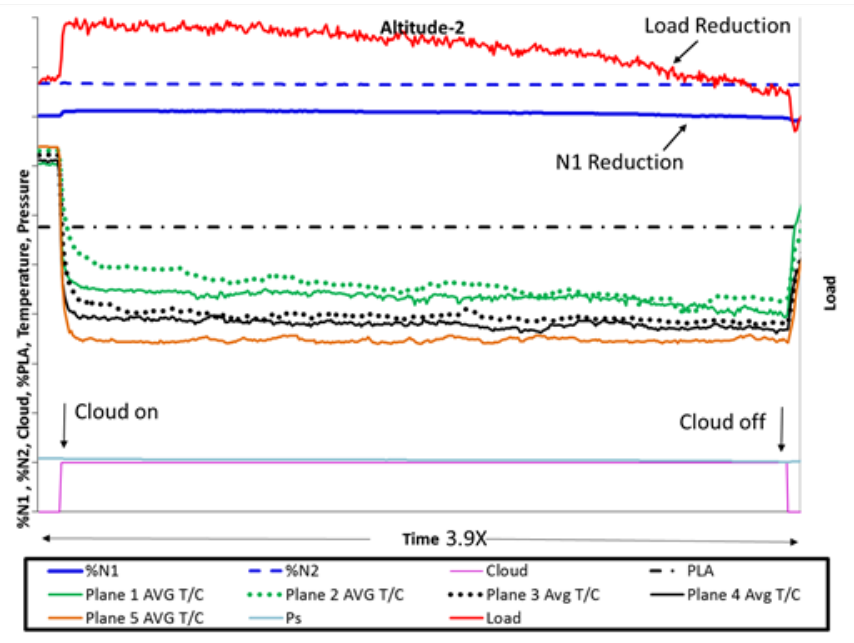

Figure 2. Altitude-2 Roll back indicator chart for the altitude scaling test condition tested in PSL. Altitude-2 < Altitude-1

\section{Altitude-3}

The chart, Altitude-3, in Figure 3 plots the PSL data generated during an ice crystal icing test point conducted at a lower altitude than Altitude-2. It should be noted that the cloud total water content was 2.4 times higher than that of the reference condition for this altitude scaling test point. From the plot it is seen that the roll back condition took $2.4 \mathrm{X}$ longer than the reference condition. The static pressure along the flow path is slightly higher than Altitude-2 but in general Altitude-3 looks similar to both the reference condition and Altitude-2. The main difference is the time to roll back. The total water content is known to be a major factor in roll back time [6]. Altitude-2 and Altitude-3 plots suggest that both altitude and total water content influence the roll back time for this test article. 


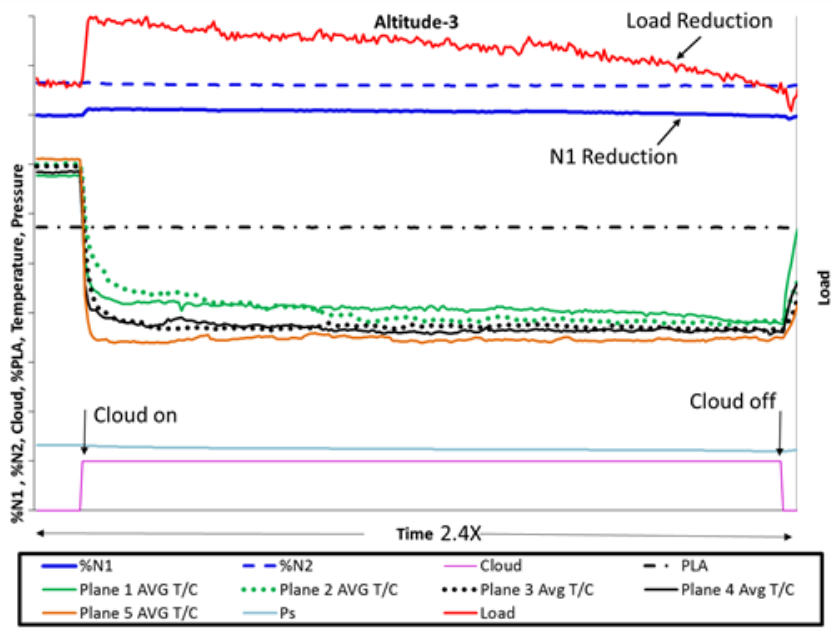

Figure 3. Altitude-3 Roll back indicator chart for the altitude scaling test condition tested in PSL. Altitude-3 < Altitude-2

\section{Altitude-4}

The chart, Altitude-4, in Figure 4 plots the PSL data generated during an ice crystal icing test point conducted at a lower altitude than Altitude-3. The total water content for this test point is the same as for Altitude- 3 and is 2.4 times higher than the reference condition. The initial run shows no changes other than the initial drop in plane temperature with cloud on. There is no convergence of plane temperatures and Ps, N1, $\mathrm{N} 2$ and PLA remain constant. A slight reduction in PLA results in a slight reduction in all the parameters but again they settle out at a steady state. A second reduction in PLA results in a slight reduction again in all the parameters but this time the plane temperatures converge and the load parameters begin to reduce over time indicating an imminent roll back condition.

The step reduction in load at each of the PLA adjustments is a result of decreased $\mathrm{N} 1$ and not due to reduced flow in the core. The Ps begins to reduce at the second PLA adjustment. It should be noted that the PLA adjustments were very minimal on the order of small perturbations and not significant changes in power lever position. The NASA model was successful at predicting the proper ambient temperature for the lower altitude conditions of Altitudes-2, and -3 but needed a little tweaking for Altitude-4. This suggests that altitude has a significant influence on ice crystal icing especially at significantly lower altitudes. Once the final PLA adjustment was made the called roll back took 1.5 times longer to occur than the reference condition which had a little more than half as much total water content in the cloud on condition.

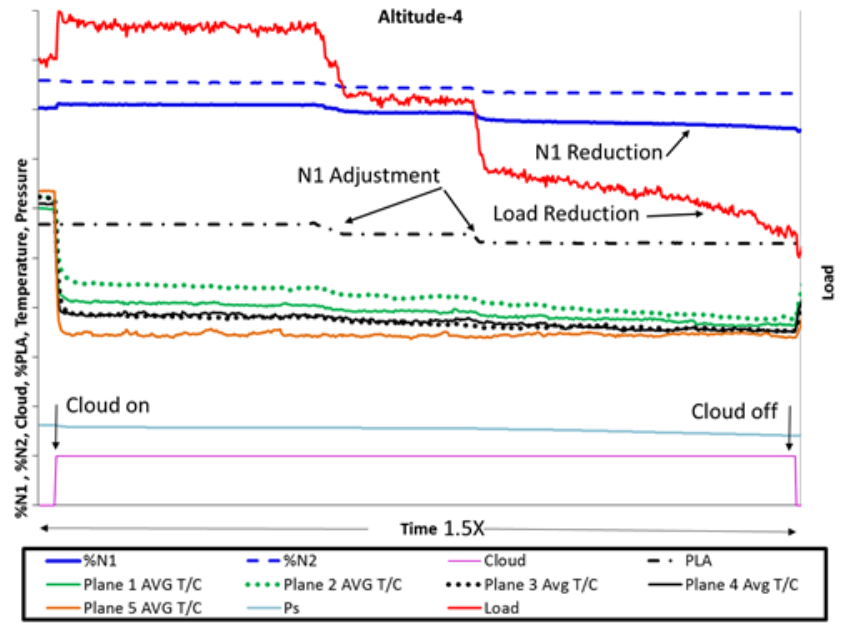

Figure 4. Altitude-4 Roll back indicator chart for the altitude scaling test condition tested in PSL. Altitude-4 < Altitude-3

\section{Altitude-5}

The chart, Altitude- 5 , in Figure 5 plots the PSL data generated during an ice crystal icing test point conducted at a lower altitude than Altitude- 4 . The total water content for this test point is the same as for Altitudes -3 , and -4 . It is 2.4 times higher than the reference condition. The static pressure along the flow path is higher than for Altitude- 4 but in general the test point looks similar to the Altitude-4 test point in that it required two PLA adjustments to induce the roll back. Once the appropriate PLA position was sufficiently adjusted, the roll back occurred 2.5 times longer than the roll back in Altitude-4. This reinforces that altitude has a significant influence on ice buildup leading to roll back for this test article.

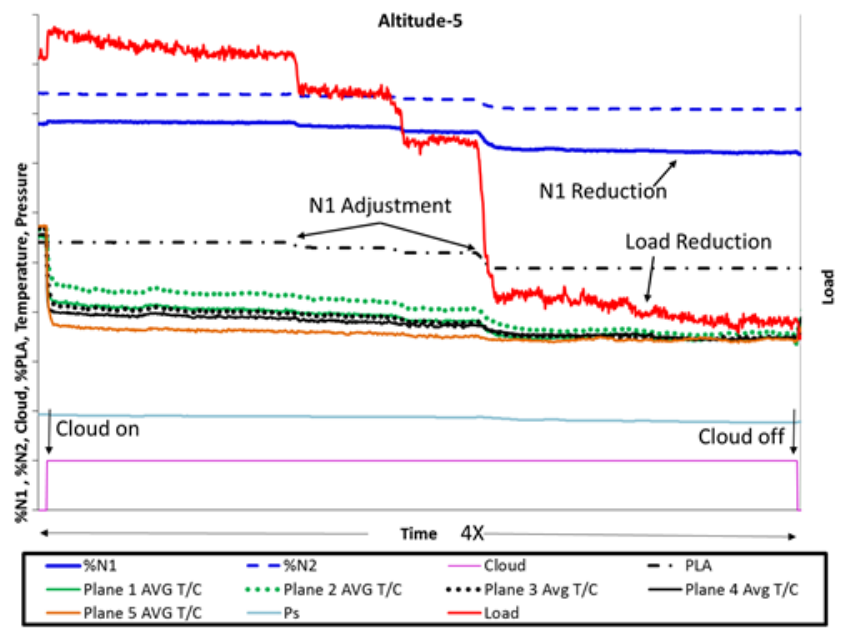

Figure 5. Altitude-5 Roll back indicator chart for the altitude scaling test condition tested in PSL. Altitude-5 < Altitude-4

\section{Discussion: Altitude Scaling Feasibility}

The PSL testing clearly demonstrated that full scale altitude scaling testing does work and is feasible for this test article. The ice crystal icing event was duplicated easily at 
consecutively lower altitudes. Future testing with internal cameras will provide additional evidence and insight as to the location and characteristics of the ice crystal icing between the high and low altitude test points. However, for some of the lower altitude test points it was necessary to hypothesize and tweak test parameters in order to replicate the ice crystal icing event. This implies that there are some physics that need to be better understood for altitude scaling. It could be said that given enough time, additional full scale testing in PSL would allow for a realistic understanding of how to simulate the high altitude ice crystal icing conditions and event at a lower altitude test condition. This does not necessarily prove that altitude scaling is feasible when applied to other turbofan engines operating in the field or on current or future the drawing boards. The objective of this altitude scaling testing conducted in PSL is to provide experimental data that allows researchers to investigate the feasibility of developing altitude scaling laws.

The concept of altitude scaling implies that a series of scaling laws can be developed that allow ice crystal icing test plans to be implemented on full scale turbofan engines at existing sea level test facilities or lower altitudes in general that duplicate the high altitude ice crystal icing flow path conditions and subsequent events—-based on the altitude scaling laws [8]. By mitigating these events or showing the engines are not susceptible to them via full scale testing at the sea level facility industry could demonstrate regulatory compliance.

Taken literally, one thought to this end is to exhaustively investigate and understand fully all of the physics, engine and environmental parameters influencing ice crystal icing at high altitude operation and duplicate the exact results in a full scale engine test at a sea level test facility by manipulating the various parameters to reproduce the high altitude ice crystal icing operational environment. Indeed this is the path of many current worldwide sponsored research efforts. Another thought is to use a facility like PSL as a research and development tool to identify key areas of an individual engine flow path that may be susceptible to ice crystal icing and work to mitigate these areas in a research and development environment. These lessons could then be incorporated into current and/or future designs. The main issue with both options however is how to ultimately demonstrate regulatory compliance.

The main driver for sea level testing is that larger fan high bypass engines require orders of magnitude more bypass airflow than PSL can deliver under high altitude ice crystal icing test conditions. Since the ice crystal icing affects the airflow through the engine compression system and not the bypass airflow, it is conceivable that researchers could use compression system rigs as their research and development test articles for the larger turbofan engines. PSL can handle the compression system airflows of even the largest turbofan engines in existence or on current drawing boards. Testing compression modules separated from the rest of the engine brings with it many issues to deal with in and of itself. These test issues are not insurmountable but they are beyond the scope of this manuscript. Suffice it to say the engine companies in addition to engineering these test rigs would need to garner support of the process from the various regulatory authorities worldwide.

The feasibility of altitude scaling testing has been demonstrated for this test article. A first attempt has been made by researchers to frame the procedures to develop altitude scaling laws for this test article [8]. The modifications giving PSL a high altitude, ice crystal icing capabilities have been built and demonstrated to work. Researchers are developing PSL test plans and fundamental experiments to better understand the physics of ice crystal icing and Industry is beginning to develop test methodologies and rigs that allow it to better understand the effects of high altitude ice crystal ingestion into their engines. It remains to be seen if altitude scaling laws are feasible to be developed that generally apply across the board for all engines experiencing ice crystal icing and allow industry to develop their engines at sea level test facilities or if individual engines will require specific altitude scaling laws based on both module testing in a facility like PSL that translate to sea level testing to demonstrate regulatory compliance.

\section{References}

1. Hooker, Stanley, J., Not Much of an Engineer, Airlife Publishing imprint of The Crowwood Press Ltd, Ramsbury, Marlborough Wiltshire SN8 2HR, 2002, Chap. 7, pp. 13637.

2. Mason, J.G., Strapp, J.W. and Chow, P., The Ice Particle Threat to Engines in Flight, 44 ${ }^{\text {th }}$ Aerospace Sciences Meeting and Exhibit, AIAA, January 9-12, 2006, Reno, NV

3. Goodwin, Ronald, V. and Dischinger, David, G., Turbofan Ice Crystal Rollback Investigation and Preparations Leading to Inaugural Ice Crystal Engine Test at NASA PSL-3 Test Facility, 6th Atmospheric and Space Environments Conference, AIAA, Atlanta, GA, June 16-20, 2014

4. Griffin, T.A., Dicki, D. J.; Lizanich, P. J.; "PSL Icing Facility Upgrade Overview", 6th AIAA Atmospheric and Space Environments Conference, American Institute of Aeronautics and Astronautics, June 2014, Atlanta, Ga.

5. Van Zante, Judith, F. and Rosine, Bryan, M., NASA Glenn Propulsion Systems Lab: 2012 Inaugural Ice Crystal Cloud Calibration Procedure and Results, 6th Atmospheric and Space Environments Conference, AIAA, Atlanta, GA, June 16-20, 2014.

6. Oliver, M.J., "Validation Ice Crystal Icing Engine Test in the Propulsion Systems Laboratory at NASA Glenn Research Center", 6th AIAA Atmospheric and Space Environments Conference, American Institute of Aeronautics and Astronautics, June 2014, Atlanta, Ga.

7. Hauser, K. and Oliver, M.J., "Ice Crystal Icing Engine Test Model Development and Sensitivity Analysis", SAE 2015 International Conference on Icing of Aircraft, Engines and Structures, Prague, Czech Republic, June 22-25, 2015.

8. Tsao, Jen-Ching, Struk, Peter, M. and Oliver, Michael, J., "Possible Mechanisms for Turbofan Jet Engine Ice Crystal icing at High Altitude", $6^{\text {th }}$ Atmospheric and Space Environments Conference, AIAA, Atlanta, GA, June 16-20, 2014

9. Veres, Joseph, P. and Jorgenson, Philip, C., "Modeling Commercial Turbofan Engine Icing Risk with Ice Crystal Contact Information 


\section{Definitions/Abbreviations}

DOE

NASA

N1

N2

PLA

Ps

PSL
Design of Experiment

National Aeronautics and

Space Administration

Fan Speed

High Pressure

Compressor Speed

Power lever angle

Static Pressure

Propulsion Systems Laboratory 


\section{Appendix}

The Appendix is one-column. If you have an appendix in your document, you will need to insert a continuous page break and set the columns to one. If you do not have an appendix in your document, this paragraph can be ignored and the heading and section break deleted. 